\title{
Bilingual children's social preferences hinge on accent
}

By: Jasmine M. DeJesus, Hyesung G. Hwang, Jocelyn B. Dautel, and Katherine D. Kinzler

DeJesus, J. M., Hwang, H. G., Dautel, J. B., \& Kinzler, K. D. (2017). Bilingual children’s social preferences hinge on accent rather than language. Journal of Experimental Child Psychology, 164, 178-191. doi: 10.1016/j.jecp.2017.07.005

(c) 2018. This manuscript version is made available under the CC-BY-NC-ND 4.0 license http://creativecommons.org/licenses/by-nc-nd/4.0/.

Made available courtesy of Elsevier: http://dx.doi.org/10.1016/j.jecp.2017.07.005

***@ Elsevier. Reprinted with permission. No further reproduction is authorized without written permission from Elsevier. This version of the document is not the version of record. Figures and/or pictures may be missing from this format of the document. ***

\begin{abstract}
:
Past research finds that monolingual and bilingual children prefer native speakers to individuals who speak in unfamiliar foreign languages or accents. Do children in bilingual contexts socially distinguish among familiar languages and accents and, if so, how do their social preferences based on language and accent compare? The current experiments tested whether 5- to 7-yearolds in two bilingual contexts in the United States demonstrate social preferences among the languages and accents that are present in their social environments. We compared children's preferences based on language (i.e., English vs. their other native language) and their preferences based on accent (i.e., English with a native accent vs. English with a non-native [yet familiar] accent). In Experiment 1, children attending a French immersion school demonstrated no preference between English and French speakers but preferred American-accented English to French-accented English. In Experiment 2, bilingual Korean American children demonstrated no preference between English and Korean speakers but preferred American-accented English to Korean-accented English. Across studies, bilingual children's preferences based on accent (i.e., American-accented English over French- or Korean-accented English) were not related to their own language dominance. These results suggest that children from diverse linguistic backgrounds demonstrate social preferences for native-accented speakers. Implications for understanding the potential relation between social reasoning and language acquisition are discussed.
\end{abstract}

Keywords: Social cognition | Bilingualism | Cognitive development | Language | Accent attitudes | Social preferences

Article:

Introduction 
Scholars across disciplines have noted a puzzling observation: Children often learn to speak like their peers, not their parents (e.g., Harris, 2009, Labov, 2009, Ochs and Schieffelin, 1995).

Linguist William Labov discussed that children's local social groups, not their parents' manner of speaking, determine the specific variations in social dialect that children exhibit in their speech (Labov, 2009). As an illustration, children of immigrants typically develop the accent of their peers (native speakers of the local language) when they arrive in a new country during early childhood despite exposure to their parents' non-native accent (Flege et al., 1995, Flege et al., 1999, Gleitman and Newport, 1995, Johnson and Newport, 1989, Newport, 1990). By adulthood, individuals who do not acquire a native phonology face challenges in communicating with others, and this in turn negatively affects feelings of social belonging (Gluszek, Newheiser, \& Dovidio, 2011). Specifically, among a group of non-native English-speaking adults, individuals who had spent fewer years living in the United States and learned English later in life were more likely to be perceived (by themselves and others) as speaking with a non-native accent, which in turn had negative consequences for both their perceived ability to successfully communicate with others in English and their feelings of social belonging in the United States. Accordingly, the motivation to feel a sense of social belonging in one's second language community, among a variety of socio-affective factors, may be related to the process of language learning (Clément, 1980, Ellis, 1997, Finegan, 1999, Gardner, 1985, Gardner and Lambert, 1972, Taylor et al., 1977). In light of these patterns observed across the lifespan, children learning the accent of their peers can have functional significance for their social experiences.

The puzzle of why and how children shift from the language and accent of their parents to that of their peers raises important questions regarding children's early language-based social preferences. A growing body of research has shown that monolingual children demonstrate robust social preferences for their native language and accent over unfamiliar languages and accents (e.g., Dailey et al., 2005, Day, 1980, Kinzler and DeJesus, 2013a, Kinzler et al., 2009) as well as preferences for monolingual over bilingual individuals (Byers-Heinlein, Behrend, Said, Girgis, \& Poulin-Dubois, 2017). For instance, monolingual White children with American accents selected potential friends who matched their accent but not their race (i.e., Americanaccented Black children) rather than children who matched their race but not their accent (i.e., French-accented White children) (Kinzler et al., 2009). In addition, children living in Hawaii preferred standard English speakers over Hawaiian Creole English speakers (with a few noteworthy exceptions to be discussed further; Day, 1980). Several studies have shown that bilingual children also demonstrate language-based social preferences (e.g., Cremona and Bates, 1977, Dailey et al., 2005, Kinzler et al., 2012, Souza et al., 2013). For instance, bilingual children in Canada preferred native-accented speakers over individuals who spoke in an unfamiliar foreign accent (Souza et al., 2013).

These studies provide an important foundation to begin to understand both monolingual and bilingual children's social preferences based on language. Nonetheless, a more ecologically valid approach would be to consider bilingual children's preferences among the languages and accents that they hear and speak themselves, which can further illuminate the mechanisms that underlie social reasoning about language. Examining the social preferences of bilingual children living in the United States is especially interesting because, although bilingualism is not the norm, a rapidly growing number of children in the United States are being raised in bilingual environments (Ryan, 2013). According to the American Community Survey (Ryan, 2013), more 
than 60 million people over 5 years of age speak a language other than English at home and more than 300 different languages are spoken in the United States. Those languages are spoken in a variety of contexts. For instance, some bilingual children in the United States speak English at home and another language at school through language immersion programs, whereas other bilingual children speak a language other than English at home with their families but are instructed in English at school and live in predominantly English-speaking communities.

The current research investigated whether two distinct populations of bilingual children in the United States socially distinguish among the languages and accents that are present in their social environments. Experiment 1 tested a group of children who attended a French immersion school in the United States. Experiment 2 tested a group of Korean American children who spoke Korean and English. We were interested in children's social preferences among the languages they heard (English and French in Experiment 1; English and Korean in Experiment 2) and how their preferences based on language compare with their preferences based on accent. Children were presented with two types of trials to examine their preferences for speakers of Americanaccented English compared with individuals who spoke in other languages or accents. On language trials, we assessed bilingual children's preference (or lack thereof) for native speakers of both their native languages (i.e., native-accented English speakers vs. native-accented French speakers in Experiment 1 and native-accented Korean speakers in Experiment 2). On accent trials, we assessed children's preferences for American-accented English compared with a nonnative, although familiar, accent in English (French-accented English in Experiment 1 and Korean-accented English in Experiment 2). Our approach is naturally limited because we examined only two examples of the language diversity present in the United States. However, these populations provide an opportunity to examine the languages and accents that bilingual children are exposed to in their local environments and represent two groups of children with relatively different linguistic experiences.

We anticipated four potential patterns of results that could shed light on the mechanisms that contribute to children's developing language- and accent-based social preferences and attitudes. One possibility is that children could select American-accented English speakers across the board given that they are living in the United States and may view English as a high-status language. Children may prioritize the dominant language in their society even if that is not the language spoken at home or in their local communities (Cremona and Bates, 1977, Dailey et al., 2005, Day, 1980, Kinzler et al., 2012; see Giles \& Billings, 2004, for a review). For example, Italian children displayed negative attitudes toward their local nonstandard dialect when they were explicitly discouraged from speaking in that dialect (Cremona \& Bates, 1977). Monolingual White and bilingual Hispanic adolescents in Southern California judged American-accented speakers as having more favorable personality traits than Spanish-accented speakers (Dailey et al., 2005). Among multilingual children in South Africa, the preference for English speakers (over Xhosa speakers) was particularly strong among children who were primarily instructed in English at school (Kinzler et al., 2012). English is not the most common first language in South Africa, yet it is often considered the language of business, commerce, and upward social mobility (De Klerk, 2000, Kamwangamalu, 2003). Relatedly, kindergarteners in Hawaii who lived in neighborhoods that were higher in socioeconomic status (SES) preferred standard English speakers, whereas children attending kindergarten in a lower SES neighborhood preferred speakers of Hawaiian Creole English (Day, 1980). If social status is a primary guide to 
children's social preferences, we might expect bilingual children in the United States to select English speakers as potential friends over individuals who speak in different languages and accents despite bilingual children's diverse linguistic experiences. Familiarity may contribute to a status-based preference for English speakers because children may also consider English to be more familiar (even if they regularly hear other languages) and familiarity itself could be an important guide to social preferences (Bernard et al., 2014, Zajonc, 2001).

Alternatively, children could select speakers as potential friends based on their own linguistic experiences. This preference could also be related to a familiarity preference but would operate through children's relative language dominance rather than broader social perceptions of English compared with other languages. Children differ in their patterns of language acquisition; for instance, in a longitudinal study of Spanish-English bilingual children in Miami, Florida, language proficiency was predicted by SES and children's home language environment (Oller \& Eilers, 2002). Children's social preferences may similarly rely on their language proficiency or may even vary in the moment based on the language spoken during the test session (for converging evidence in adults, see Danziger and Ward, 2010, Ogunnaike et al., 2010). For instance, English-dominant children may select English speakers as potential friends over French or Korean speakers, whereas French- or Korean-dominant children may select French or Korean speakers over English speakers. These results would be distinguishable from a general preference for English based on status or familiarity because one could expect to see robust effects of language dominance or testing environment on children’s responses.

As a third possibility, children could select native-accented speakers as potential friends but might not differentiate between native speakers of their two languages. Such a response would be distinct from a general English preference because children would not choose a native English speaker over a native speaker of their other language as a potential friend, yet they would prefer native-accented speakers over non-native speakers regardless of language dominance or testing environment. Bilingual children could demonstrate an equal preference for native speakers of all the languages they hear and speak regularly, yet they might still show a preference for an individual who speaks with a native accent over an individual who speaks with a non-native accent even if that accent is one they likely hear in their community.

Finally, it is possible that bilingual children might not differentiate between speakers of languages and accents that are present in their social environment. If children have some familiarity with the languages and accents presented to them, they may view all speakers equally positively and consequently might not reliably show a social preference among speakers of these familiar languages and accents. Although bilingual children preferred speakers with native accents over speakers with an unfamiliar foreign accent (Souza et al., 2013), it is possible that children might not demonstrate the same preference when presented with speakers who are more familiar to them either through experience with the phonology of their other language or from directly hearing people speak English with non-native accents. Although many factors mentioned previously — such as social status, linguistic experience, and familiarity-may influence children's social preferences in different contexts, several predictions can be evaluated in the current design: (a) a general preference for English speakers, (b) a preference for English speakers related to bilingual children’s language exposure, (c) a specific preference for native- 
accented speakers (but not necessarily for English speakers over speakers of their other language), and (d) no preference at all.

\section{Experiment 1: French- and English-speaking children}

Experiment 1 tested children attending a French immersion school. Children were presented with pairs of speakers in language trials (English vs. French) and accent trials (American-accented English vs. French-accented English) and were asked to select one potential friend out of each pair of speakers.

Method

Participants

Participants in Experiment 1 were 40 5- to 7-year-old children (20 girls and 20 boys; mean age $=76.8$ months, range $=63.7-89.3$; in terms of race, 34 were White, 4 were multiracial, and 2 were other/not reported). The majority of participants (30 of 40) were born in the United States; the remaining 10 were born in Canada $(n=2)$ and Europe (France, $n=4$; Austria, $n=1$; Belgium, $n=1$; United Kingdom, $n=1$ ) or birthplace was not reported $(n=1)$. Participants were recruited from a French immersion school in Chicago, Illinois, where instruction is primarily in French at all grade levels. All participants had at least basic proficiency in both languages. Parents of participants varied in their language backgrounds; of the 40 children, 15 had two native English-speaking parents, 4 had two native French-speaking parents, 7 had one native English-speaking parent and one native French-speaking parent, and the remaining 14 children had parents who were native speakers of a third language or did not report their language background. The majority (70\%) of parents reported having a bachelor's degree or higher. See Table 1 for more information about the language background of participants and their parents.

Materials and procedure

Children were presented with 16 social preference trials (8 language trials and 8 accent trials). In each trial, an experimenter showed the child a pair of faces and pointed to each face while playing a corresponding voice clip. After both voice clips were played, the experimenter asked which member of the pair the child would "want to be friends with." The child responded by pointing to his or her selection's face.

The face stimuli set consisted of faces of adults and children who were racially ambiguous. Faces were created by morphing White and Black faces using face morphing software (Morpheus). Face pairs were gender and age matched (i.e., two male children, two female children, two male adults, or two female adults per trial).

The voice stimuli consisted of native English and French voice clips for language trials (see Byers-Heinlein et al., 2017, and Kinzler et al., 2009, for related trials) and Americanaccented and French-accented English voice clips for accent trials (see Kinzler and DeJesus, 2013a, Kinzler et al., 2009, and Souza et al., 2013, for related trials) recorded from adults and 
children. All clips featured child-friendly neutral content (e.g., "There are seven colors in the rainbow”). For adult voice clips, the same bilingual French-English speakers recorded voice clips in American-accented English, French-accented English, and French-accented French and were paired using a matched-guise technique (i.e., each trial included two voice clips from the same individual) to control for pitch, warmth, and other aspects of voice quality (see Lambert, Hodgson, Gardner, \& Fillenbaum, 1960). For child voice clips, native French-speaking children in France recorded voice clips in French and French-accented English, whereas Americanaccented English voice clips were recorded from monolingual English-speaking children in the United States (the matched-guise technique was not employed; each child trial featured two speakers).

Table 1. Language information for participants and their parents.

\begin{tabular}{|c|c|c|c|}
\hline & & $\begin{array}{l}\text { Experiment 1: } \\
\text { French } \\
\text { immersion } \\
(N=39)\end{array}$ & $\begin{array}{l}\text { Experiment 2: } \\
\text { Korean } \\
\text { American } \\
(N=22)\end{array}$ \\
\hline \multirow[t]{5}{*}{ Child English proficiency $[\%(n)]$} & Basic & $2.6(1)$ & $18.2(4)$ \\
\hline & Proficient & $5.1(2)$ & $22.7(5)$ \\
\hline & Highly fluent & $10.3(4)$ & $9.1(2)$ \\
\hline & Native & $79.5(31)$ & $50.0(11)$ \\
\hline & Did not report & $2.6(1)$ & $0.0(0)$ \\
\hline \multirow[t]{5}{*}{ Child French/Korean proficiency [\% $(n)]$} & Basic & $5.1(2)$ & $40.9(9)$ \\
\hline & Proficient & $30.8(12)$ & $9.1(2)$ \\
\hline & Highly fluent & $17.9(7)$ & $13.6(3)$ \\
\hline & Native & $35.9(14)$ & $36.4(8)$ \\
\hline & Did not report & $10.3(4)$ & $0.0(0)$ \\
\hline \multirow[t]{4}{*}{ Child language dominance $[\%(n)]$} & English dominant & $51.3(20)$ & $40.9(9)$ \\
\hline & French/Korean dominant & $15.4(6)$ & $27.3(6)$ \\
\hline & Equal & $20.5(8)$ & $31.8(7)$ \\
\hline & Did not report & $12.8(5)$ & $0.0(0)$ \\
\hline \multirow[t]{4}{*}{ Child hears/speaks English [\%(n)] } & Home and school & $76.9(30)$ & $81.8(18)$ \\
\hline & Home only & $7.7(3)$ & $0.0(0)$ \\
\hline & School only & $12.8(5)$ & $18.2(4)$ \\
\hline & Did not report & $2.6(1)$ & $0.0(0)$ \\
\hline \multirow[t]{4}{*}{ Child hears/speaks French/Korean $[\%(n)]$} & Home and school & $76.9(30)$ & $81.8(18)$ \\
\hline & Home only & $7.7(3)$ & $0.0(0)$ \\
\hline & School only & $12.8(5)$ & $18.2(4)$ \\
\hline & Did not report & $2.6(1)$ & $0.0(0)$ \\
\hline \multirow[t]{4}{*}{ Peer language $[\%(n)]$} & English and French/Korean & $69.2(27)$ & $63.6(14)$ \\
\hline & English only & $28.2(11)$ & $27.3(6)$ \\
\hline & French/Korean only & $2.6(1)$ & $4.5(1)$ \\
\hline & Did not report & $0.0(0)$ & $4.5(1)$ \\
\hline \multirow[t]{8}{*}{ Parent native language $[\%(n)]$} & Both parents English & $38.5(15)$ & $0.0(0)$ \\
\hline & Both parents French/Korean & $10.3(4)$ & $59.1(13)$ \\
\hline & $\begin{array}{l}\text { Both parents bilingual } \\
\text { (English-French, English-Korean) }\end{array}$ & $0.0(0)$ & $4.5(1)$ \\
\hline & 1 English, 1 French/Korean & $17.9(7)$ & $9.1(2)$ \\
\hline & 1 English, 1 other/no report & $7.7(3)$ & $0.0(0)$ \\
\hline & 1 French/Korean, 1 other/no report & $5.1(2)$ & $9.1(2)$ \\
\hline & Both parents other & $7.7(3)$ & $0.0(0)$ \\
\hline & Both parents did not report & $12.8(5)$ & $18.2(4)$ \\
\hline
\end{tabular}

Note. One child from Experiment 1 is excluded from this table because no questionnaire was received for that child. 


\section{Design and analyses}

Children were tested in either English or French (17 English and 23 French) by a bilingual speaker of English and French. Language and accent trials were presented in blocks of 4 trials in alternating order (e.g., 4 language, 4 accent, 4 language, 4 accent). The pairings of voice to face, the order in which contrasts were presented, and the language used by the experimenter during the testing session (English or French) all were counterbalanced across participants, whereas the block order was counterbalanced both within and across participants.

Children's responses were analyzed using a repeated-measures analysis of variance (ANOVA) with trial type (language vs. accent) and target age (adult vs. child) entered as within-participants factors. In addition, participants' performance on language and accent trials were compared to chance (50\%) using two-tailed one-sample $t$ tests. A preliminary analysis revealed no main effect of test language in Experiment $1, F(1,38)=0.61, p=.44, \eta_{\mathrm{p}}{ }^{2}=.02$, in Experiment 2, $F(1,20)=1.72, p=.21, \eta_{\mathrm{p}}^{2}=.08$, or combined across experiments, $F(1,60)=1.69, p=.20, \eta_{\mathrm{p}}{ }^{2}=.03$. Therefore, we collapsed across test language in subsequent analyses.

\section{Results}

Children tested at a French immersion school treated language and accent trials differently when their friendship preferences were assessed, $F(1,39)=19.80, p<.001, \eta_{\mathrm{p}}{ }^{2}=.34$. When presented with a contrast between English and French speakers, children did not significantly prefer either speaker as a potential friend $\left(M_{\text {English }}=53.8 \%, S E=4.93\right), t(39)=0.76, p=.45, d=0.24$.

However, when presented with a contrast between American- and French-accented speakers of English, children significantly preferred the American-accented English speakers $\left(M_{\text {Native }}=74.4 \%, S E=4.00\right), t(39)=6.09, p<.001, d=1.95$ (see Fig. 1 , left $)$.

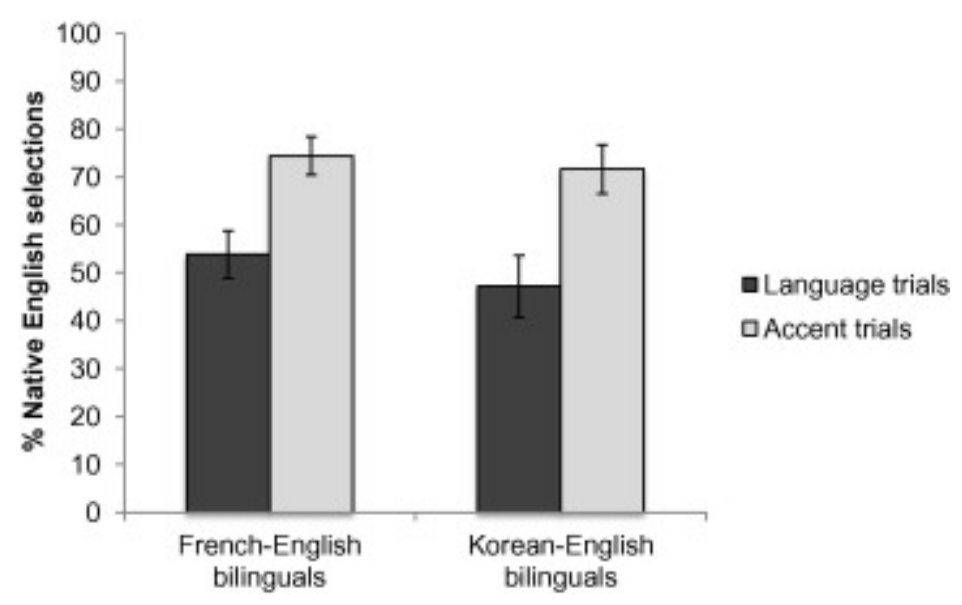

Fig. 1. Results from bilingual French- and English-speaking children tested at a French immersion school (Experiment 1, left) and bilingual Korean- and English-speaking children (Experiment 2, right). 
We also observed a marginally significant effect of target age, $F(1,39)=3.14, p=.084, \eta_{\mathrm{p}}{ }^{2}=.07$. Children were slightly more likely to select nativeaccented English speakers (over French speakers or French-accented English speakers) when presented with adult speakers $\left(M_{\text {English }}=65.3 \%, S E=3.99\right)$ than when presented with child speakers $\left(M_{\text {English }}=60.3 \%, S E=3.90\right)$. No significant interaction between trial type and target age was observed, $F(1,39)=0.15, p=.70, \eta_{\mathrm{p}}{ }^{2}=.004$.

\section{Discussion}

Children tested at the French immersion school did not express a preference for English speakers or French speakers, but they did make clear distinctions based on accent; they selected American-accented English speakers as friends over French-accented speakers of English. These results build on past research finding that children prefer native-accented speakers over speakers of an unfamiliar accent (Kinzler and DeJesus, 2013a, Kinzler et al., 2009, Souza et al., 2013) and extend these findings by presenting bilingual children with languages and accents that are familiar to them. Children preferred native-accented English compared with a non-native (yet familiar) accent. Moreover, children's preferences based on accent appear to be stronger in this case than preferences between their two languages. We found only limited effects of target age on children's perceptions of speakers of different languages and accents; children were marginally more likely to select native English speakers (over French speakers or Frenchaccented English speakers) when viewing adults than when viewing children, but with no interaction with trial type. These initial results provide evidence for the third accent-specific possibility outlined previously in which children are specifically attuned to native-accented speech rather than a particular language they speak.

Nonetheless, it should be noted that the population tested in Experiment 1 is a heterogeneous group of children with diverse linguistic experiences. These children shared a common educational environment in which French was the language of instruction (an environment their parents intentionally selected), yet their home language environments differed greatly. For instance, a child in this sample with one native English-speaking parent and one native Frenchspeaking parent likely hears a different mix of languages and accents at home than a child with two monolingual English-speaking parents. Thus, Experiment 2 sought to extend these questions to a group of children with a different bilingual experience in the United States. Specifically, we recruited a group of bilingual Korean American children who primarily hear Korean at home and in their communities but hear English at school.

\section{Experiment 2: Korean- and English-speaking children}

Experiment 2 tested a group of children who speak both English and Korean and assessed their social preferences according to language (English vs. Korean) and accent (American-accented English vs. Korean-accented English).

\section{Method}

Participants 
Participants were 22 5- to 7-year-old children (10 girls and 12 boys; mean age $=76.2$ months, range $=60.9-88.4)$. All participants were ethnically Korean, and 18 of 22 were born in the United States (4 were born in South Korea). Participants were recruited from the Chicago and Columbus, Ohio, areas at local schools, churches, and other community centers. All children had at least basic proficiency in both Korean and English, and all children had regular exposure to Korean at home and in their community. In addition, 21 of 22 participants received tutoring in Korean.

Among the parents of participating children, 43 of 44 parents were born in South Korea (1 parent was born in the United States). Parents were provided with the option of filling out consent forms and questionnaires in either English or Korean; of 22 form packets, 20 were returned in Korean. All children had at least one parent who reported being a native Korean speaker; for 15 children, both parents reported being native Korean speakers. The majority (61\%) of parents reported receiving a bachelor's degree or higher. See Table 1 for more information about the language background of participants and their parents.

\section{Materials and procedure}

The face stimuli set consisted of photographs of Asian children and adults (8 male children, 8 female children, 8 male adults, and 8 female adults, all ethnically Korean). As in Experiment 1, face pairs were gender and age matched. The voice stimuli set consisted of native English, native Korean, and Korean-accented English speech recorded from adults and children. For adult voice clips, two bilingual speakers recorded voice clips in American-accented English and Koreanaccented Korean (the matched-guise technique was employed for adult language trials; each trial featured two voice clips from the same individual). Four native speakers of Korean who immigrated to the United States after adolescence provided the Korean-accented English voice clips (the matched-guise technique was not employed for adult accent trials; each adult accent trial featured two speakers). For child voice clips, two native speakers of Korean recorded voice clips in Korean-accented Korean and two native speakers of Korean who had been living in the United States for less than 3 months recorded the Korean-accented English voice clips. Monolingual English-speaking children in the United States recorded the Americanaccented English voice clips (the matched-guise technique was not employed for child trials; each child trial featured two speakers).

The procedure was identical to that of Experiment 1. In language trials, children heard one clip of native English speech and one clip of native Korean speech. In accent trials, children heard one clip of American-accented English speech and one clip of Korean-accented English speech. On each trial, children were asked who they would "want to be friends with."

Design and analysis

Children were tested in either Korean or English (9 in Korean and 13 in English) by a bilingual speaker of Korean and English. Language and accent trials were presented in blocks of 4 trials as in Experiment 1. The pairings of voice to face, the order in which contrasts were presented, and test language (English or Korean) were counterbalanced across participants; block order was counterbalanced both within and across participants. As in Experiment 1, children's responses 
were analyzed using a repeated-measures ANOVA with trial type (language vs. accent) and target age (adult vs. child) entered as within-participants factors, and their choices of nativeaccented English voices were compared to chance (50\%) using two-tailed one-sample $t$ tests.

\section{Results}

Bilingual Korean American children also treated language and accent trials differently when their friendship preferences were assessed, $F(1,21)=9.30, p=.006, \eta_{\mathrm{p}}{ }^{2}=.31$. For language trials, children in Experiment 2 did not express a preference for English speakers over Korean speakers $\left(M_{\text {English }}=47.2 \%, S E=6.47\right), t(21)=-0.43, p=.67, d=0.19$. In contrast, for accent trials, they chose American-accented English speakers over Korean-accented English speakers $\left(M_{\text {Native }}=71.6 \%, S E=5.08\right), t(21)=4.25, p<.001, d=1.85$ (see Fig. 1 , right $)$.

We observed no significant effect of target age, $F(1,21)=2.55, p=.13, \eta_{\mathrm{p}}{ }^{2}=.11$, or interaction between trial type and target age, $F(1,21)=0.47, p=.50, \eta_{\mathrm{p}}^{2}=.02$.

\section{Discussion}

The results of Experiment 2 showed a strikingly similar pattern to those of Experiment 1. Bilingual Korean American children also preferred native-accented English speakers compared with individuals who spoke in a non-native (yet familiar) accent. Furthermore, children's preferences based on accent were also stronger in this case than their preferences between their two languages. Thus, accent appears to play a powerful role in guiding children's social preferences even among different groups of bilingual children.

To briefly summarize the findings of the current research so far, children who regularly heard more than one language did not demonstrate a social preference between native speakers of English and their other language, yet they robustly preferred American-accented English speakers over non-native English speakers. We observed notable similarities in children's responses across two different populations of children with diverse linguistic experiences. Nevertheless, it is possible that children's specific experiences may influence the extent to which they prefer American-accented English. For instance, dominance in English compared with children's other language may be related to their preference for English speakers or vice versa. To test this possibility, we conducted an additional analysis that included language dominance (English, French/Korean, or equal), collapsing across experiments to provide additional power.

Dominance was determined based on parental report of their children's language proficiency. Parents were asked to rate their children's proficiency in English and French/Korean on a 4-point scale (ranging from basic to native speaker; see Table 1). Children whose proficiency in English was rated as higher than their proficiency in French/Korean were classified as English dominant ( $n=32$; 23 French-English speakers and 9 Korean-English speakers), children whose proficiency in French/Korean was rated higher than their proficiency in English were classified as French/Korean dominant $(n=13 ; 7$ French-English speakers and 6 Korean-English speakers), and children who had the same proficiency score in both languages were classified as equal ( $n=16$; 9 French-English speakers and 7 Korean-English speakers). One additional child 
from Experiment 1 was excluded from this analysis because we did not receive a language questionnaire for that child.

We conducted a repeated-measures ANOVA with trial type (language vs. accent trials) entered as a within-participants factor and language dominance (English vs. French/Korean vs. equal) entered as a between-participants factor. We again observed a significant effect of trial type, $F(1,58)=32.10, p<.001, \eta_{\mathrm{p}}{ }^{2}=.36$, indicating that children were more likely to select the native English speaker when compared with a non-native English speaker $\left(M_{\text {Native }}=73.0 \%, S E=3.46\right)$ than when compared with a native speaker of children's other language $\left(M_{\text {English }}=48.3 \%, S E=4.12\right)$. There was no main effect of language dominance, $F(1,58)=1.34, p=.27, \eta_{\mathrm{p}}^{2}=.04$, but there was a significant interaction between trial type and language dominance, $F(2,58)=3.43, p=.039, \eta_{\mathrm{p}}{ }^{2}=.11$.

To examine this interaction, we conducted separate one-way ANOVAs for each trial type, with dominance entered as a between-participants factor. We observed no effect of language dominance on accent trials, $F(2,58)=0.25, p=.78$, but there was a significant effect of language dominance on language trials, $F(2,58)=3.28, p=.045$. Post-hoc Tukey HSD (honestly significant difference) tests revealed that English-dominant children were significantly more likely to select the English speaker over the French or Korean speaker $\left(M_{\text {English }}=57.4 \%, S E=4.92\right)$ than children who were French- or Korean- dominant $\left(M_{\text {English }}=32.7 \%, S E=7.15\right), p=.039$. Children who were equally proficient did not significantly differ in their selection of English speakers $\left(M_{\text {English }}=54.7 \%, S E=9.12\right)$ from English-dominant children, $p=.95$, or French- or Korean-dominant children, $p=.129$. Further analyses employing one-sample $t$ tests revealed that English-dominant children and children who were equally proficient in both languages did not select English speakers more often than would be predicted by chance [English dominant: $t(31)=1.51, p=.14, d=0.54$; equal: $t(15)=0.51, p=.62, d=0.26]$, whereas French- or Korean-dominant children selected French or Korean speakers more often than would be expected by chance, $t(12)=-2.42, p=.032, d=1.40$.

This analysis reveals two important findings. First, children's preference for native-accented English speakers over individuals who spoke in non-native (yet familiar) accents was invariant to children's own language proficiency. Regardless of their language dominance, children preferred native-accented English speakers over individuals who spoke in a non-native accent. Second, children's preference for native English speakers over native speakers of another language they speak was influenced by children's language proficiency. Specifically, children who were dominant in English or had equal proficiency in both languages did not demonstrate a preference for either English speakers or speakers of their other language, whereas children who were dominant in either French or Korean selected French and Korean speakers as potential friends. Although we are cautious in our interpretation because our sample of children dominant in either French or Korean was small, this finding provides preliminary evidence that children's specific linguistic experiences are relevant to their social preferences based on language, a topic we return to in the General Discussion.

\section{General discussion}


These findings provide evidence that children from diverse linguistic backgrounds express social preferences for native-accented speakers when choosing among languages and accents that are present in their social environment. Children who spoke English and either French or Korean robustly preferred American-accented English speakers to French- or Korean-accented English speakers, although they did not show related preferences for English over their other language. These results suggest that bilingual children can socially discriminate among accents (see also Souza et al., 2013) but do not necessarily discriminate among native speakers of different familiar languages (see Byers-Heinlein et al., 2017, for converging evidence in bilingual children's judgments of monolingual vs. bilingual speakers). Even though they were presented with accents that they are exposed to in their social environments (and, in the Korean American sample, accents that may be similar to those spoken by their parents), bilingual children in this study demonstrated a strong social preference for native-accented English speakers.

This pattern of results does not reflect a broad preference for speakers of English, as might have been expected if English were viewed by children in this study as the prestige language in the United States. Nevertheless, we tested only two populations of bilingual American children, and it is possible that children in other social environments may perceive English to be higher status than their other language. Interestingly, we found that children's language background was not related to their accent-based social preferences. Whether children were dominant in English or another language (or were equally proficient in both languages), children preferred English speakers who spoke with a native accent over English speakers who spoke with a non-native accent. However, children's language dominance appears to be somewhat related to their language-based social preferences; on language trials, English-dominant children were relatively more likely to select English speakers as potential friends compared with French- or Koreandominant children, although English-dominant children still did not select English speakers more often than would be predicted by chance (French/Korean-dominant children did select French and Korean speakers more than would be predicted by chance, although this sample was small). These patterns suggest that children's language learning and environment may be related to their social preferences based on language but not on accent. Instead, bilingual children's preference for native-accented speakers over non-native speakers was invariant across children with different linguistic experiences.

These results contribute to our understanding of children's early social preferences based on language and accent in two important ways. First, these findings paint a descriptive picture of language- and accent-based social preferences. Children live in incredibly diverse linguistic environments around the world, and recruiting populations of bilingual children with different experiences provides insight into how those experiences might contribute to their social preferences. The current findings describe the experiences and social preferences of a group of children that is not frequently studied in the United States (compared with the breadth of research with monolingual children) yet is a growing portion of the population (see Nielsen, Haun, Kärtner, \& Legare, 2017, for a call for increasing diversity in developmental psychology research more broadly). Second, these findings provide insight into the mechanisms that shape children's early social preferences by examining a set of languages and accents that are familiar to participants. The bilingual children tested in the current research demonstrated preferences for native-accented speakers but not necessarily the dominant language of their society. 
These results demonstrate striking similarities in the responses of two different populations of bilingual children in the United States. In Experiment 1, we tested a group of children attending a French immersion school, whose parents specifically sought out this educational environment. In Experiment 2, we tested a group of Korean American bilingual children, who primarily hear Korean at home and English at school. Nevertheless, as we noted previously, examining populations of bilingual children with different experiences would provide additional insights into the population-level factors that might contribute to the development of children's social preferences. The strength of the accents that bilingual children hear may also play a role in children's social judgments. Although we did not examine accent strength in this study, it is possible that the strength of a person's accent may influence children's social perceptions of that person. Even relatively young children can draw distinctions based on subtle differences in the ways in which other people speak, including non-native accents, regional accents, and registers (Jones et al., 2017, Kinzler and DeJesus, 2013b, Wagner et al., 2010), and this capacity increases across early childhood (Floccia et al., 2009, Jones et al., 2017). It is possible that children's social preferences may track, at least in part, with their perception of the strength of an individual's accent. For instance, adults judged accented speakers more harshly when they had difficulty in processing their speech (i.e., because participants were listening to speakers in a noisy environment) compared with when they did not have difficulty (Dragojevic \& Giles, 2016). Thus, future studies should investigate whether speakers' accent strength influences both monolingual and bilingual children's social preferences.

\section{Considering the role of familiarity}

Familiarity certainly plays a role in guiding early social preferences. Even brief or subliminal exposure to a stimulus can engender liking of that stimulus (see Zajonc, 2001, for a review), and this certainly must be the case for languages as well. There may also be important links between familiarity and ease of processing that guide children's perceptions of speech. Children are more likely to endorse fluent statements than disfluent ones (i.e., audio recordings with noise added; Bernard et al., 2014). Children also presumably find more familiar speech to be easier to process given that adults demonstrate more positive attitudes toward accented speakers when they are in quieter environments and that speech is easier to process compared with noisy environments (Dragojevic \& Giles, 2016). We also find some evidence for the possibility that familiarity can guide children's social preference; English-dominant children were more likely to select English speakers as potential friends than French- or Korean-dominant children. However, relative familiarity and ease of processing might not fully account for these findings. If familiarity were solely responsible for children's preferences, we would expect Englishdominant children to select English speakers as potential friends at above chance levels. Children did not show a reliable preference for speakers of English over speakers of their other language. In contrast, children did demonstrate robust preferences for native-accented speakers of English against familiar (yet non-native-accented) speakers of English regardless of their own linguistic experiences. We posit that familiarity and social categorization likely work in concert to explain children's developing language-based social preferences, with past literature documenting children's social preference for higher status speech despite it being less familiar to them (e.g., in the case of South Africa, Kinzler et al., 2012). 
Additional studies with monolingual children provide converging evidence that children's social preferences are dissociable from their ability to understand a particular speaker; when children were presented with individuals who spoke with either a native or non-native accent, yet both individuals conveyed information without meaningful semantic content, children subsequently chose to learn nonverbal information from the native-accented speaker. This is striking because neither speaker had previously provided meaningful linguistic content (Kinzler, Corriveau, \& Harris, 2011). In another study, monolingual English-speaking children demonstrated no social preference between French speakers and French-accented English speakers but were significantly more likely to report that they understood the French-accented English speaker better than the French speaker (Kinzler et al., 2009). Together, these findings suggest that although familiarity certainly plays a role in guiding preferences, children are also sensitive to the social significance of accent. Future research that can more precisely quantify the amount of time bilingual children spend hearing different languages and accents and can differentiate among input from parents, peers, teachers, and media could provide additional insight into how familiarity contributes to children’s social reasoning about language.

\section{Social preferences and language learning}

The data presented here may also provide a potential point of contact with research on language learning. In the United States, children who are exposed to a non-native accent of English at home (i.e., from their parents who are learning English) typically develop a native-sounding phonology of English themselves (e.g., Flege et al., 1995, Flege et al., 1999). The extent to which children can acquire a native phonology may have important consequences for their communicative success and feelings of social belonging later in life, and the motivation to achieve a sense of belonging is related to success at learning new languages (Clément, 1980, Ellis, 1997, Finegan, 1999, Gardner, 1985, Gardner and Lambert, 1972, Gluszek et al., 2011, Taylor et al., 1977). Children's social preferences for native-accented speech in a given language and their learning of that language, therefore, could have reciprocal influences. Given that adults subtly adjust their speech patterns to mimic people who they socially prefer (e.g., Babel, 2010, Babel, 2012), children's social preference for native-accented speakers may provide a similar model for language development among children who are regularly exposed to different languages and accents. Acquiring a native accent may in turn provide social benefits for bilingual children given that their peers likely also prefer native-accented individuals. These relations may provide insight into the emergence of language- and accent-based social attitudes. Children might not necessarily dislike people who speak in foreign languages or accents (see Cameron, Alvarez, Ruble, \& Fuligni, 2001, for a related discussion about race) or believe that native speakers are "smarter" or more competent than non-native speakers (Kinzler \& DeJesus, 2013a), but tuning into native speakers may nonetheless provide social benefits. Understanding the scope and complexity of children's language-based social preferences, especially as it may pertain to early language acquisition or experiences with diverse groups of speakers, is an important question for future research.

Further study of the effects of language dominance and exposure could shed additional light on the link between language learning and social preferences. An important limitation to consider about the current research is that children could not be randomly assigned to a language dominance category, so perhaps the same factors that give rise to differences in language 
dominance also have consequences for children's social reasoning. Children who are living in the United States yet are dominant in a language other than English likely have different cultural experiences from children who are exposed to multiple languages but are dominant in English. Examining the relation between language dominance and linguistic and cultural exposure could shed light on the role of social experiences in children's language learning. Certainly, we would expect language dominance and exposure to be correlated, but this association may differ across children. If so, social experiences could be related to the precise amounts of language exposure multilingual children receive and children's resulting proficiency in each language they speak.

\section{Learning what is native}

How children learn who is part of their linguistic ingroup and about the relative social status of different languages and accents in their community is an important and complex question. Discerning which languages or accents are native must initially be based on familiarity. Indeed, preferences for one's native language are expressed early in development (Kinzler et al., 2007, Nazzi et al., 1998), and infants begin to lose the ability to discriminate non-native phonemes without continued exposure to other languages (Werker \& Tees, 1984). The amount of exposure children have to non-native-accented speakers likely also contributes to their perceptions of those speakers, as does their ability to recognize the words spoken by those individuals (see Bergelson and Swingley, 2017, Potter and Saffran, 2017). In addition to exposure, implicit social learning likely plays an important role in how children assign social value to their native language(s) and to other languages and accents they might hear. Children are aware of the social structures of their communities from an early age, and much of this learning is likely implicit rather than being acquired through explicit statements about the link between groups and status (see Olson, Shutts, Kinzler, \& Weisman, 2012;Shutts, Brey, Dornbusch, Slywotzky, \& Olson, 2016, for related studies of children's association between SES and race). These associations may take on many forms, including social preferences, as documented in the current research and studies of children's judgments about nationality or geographic background (DeJesus et al., 2017, Weatherhead et al., 2016). The origins and scope of children's language- and accent-based social preferences, therefore, are important topics for further study.

\section{Acknowledgments}

This research was supported in part by National Institute of Child Health and Human Development (NICHD) Grant R01 HD070890 to K.D.K., a National Science Foundation(NSF) Graduate Research Fellowship (DGE-1144082) to J.M.D., and an Earl Franklin Research Fellowship to H.G.H. We thank Anais Challe for assistance in data collection and members of the Development of Social Cognition Lab and two anonymous reviewers for helpful comments on a previous version of the manuscript.

\section{References}

Babel, M. (2010). Dialect divergence and convergence in New Zealand English. Language in Society, 39, 437-456. 
Babel, M. (2012). Evidence for phonetic and social selectivity in spontaneous phonetic imitation. Journal of Phonetics, 40, 177-189.

Bergelson, E., \& Swingley, D. (2017). Young infants’ word comprehension given an unfamiliar talker or altered pronunciations. Child Development. Advance online publication. doi: http://dx.doi.org/10.1111/cdev.12888.

Bernard, S., Proust, J., \& Clément, F. (2014). The medium helps the message: Early sensitivity to auditory fluency in children's endorsement of statements. Frontiers in Psychology, 5.

http://dx.doi.org/10.3389/fpsyg.2014.01412.

Byers-Heinlein, K., Behrend, D. A., Said, L. M., Girgis, H., \& Poulin-Dubois, D. (2017).

Monolingual and bilingual children's social preferences for monolingual and bilingual speakers.

Developmental Science, 20, e12392.

Cameron, J. A., Alvarez, J. M., Ruble, D. N., \& Fuligni, A. J. (2001). Children’s lay theories about ingroups and outgroups: Reconceptualizing research on prejudice. Personality and Social Psychology Review, 5, 118-128.

Clément, R. (1980). Ethnicity, contact, and communicative competence in a second language. In H. Giles, W. P. Robinson, \& P. M. Smith (Eds.), Language: Social psychological perspectives (pp. 147-154). Oxford, UK: Pergamon.

Cremona, C., \& Bates, E. (1977). The development of attitudes toward dialect in Italian children. Journal of Psycholinguistic Research, 6, 223-232.

Dailey, R. M., Giles, H., \& Jansma, L. L. (2005). Language attitudes in an Anglo-Hispanic context: The role of the linguistic landscape. Language \& Communication, 25, 27-38.

Danziger, S., \& Ward, R. (2010). Language changes implicit associations between ethnic groups and evaluation in bilinguals. Psychological Science, 21, 799-800.

Day, R. (1980). The development of linguistic attitudes and preferences. TESOL Quarterly, 14, 27-37.

De Klerk, V. (2000). To be Xhosa or not to be Xhosa Ellipsis that is the question. Journal of Multilingual and Multicultural Development, 21, 198-215.

DeJesus, J. M., Hwang, H. G., Dautel, J. B., \& Kinzler, K. D. (2017). “'American = Englishspeaker” before “American = White”: The development of children's reasoning about nationality. Child Development. Advance online publication. doi: http://dx.doi.org/10.1111/cdev.12845.

Dragojevic, M., \& Giles, H. (2016). I don’t like you because you're hard to understand: The role of processing fluency in the language attitudes process. Human Communication Research, 42, 396-420. 
Ellis, R. (1997). The study of second language acquisition. Oxford, UK: Oxford University Press.

Finegan, E. (1999). Language: Its structure and use (3rd ed.). San Diego: Harcourt Brace.

Flege, J. E., Munro, M. J., \& MacKay, I. R. (1995). Factors affecting strength of perceived foreign accent in a second language. Journal of the Acoustical Society of America, 97, 31253134.

Flege, J. E., Yeni-Komshian, G. H., \& Liu, S. (1999). Age constraints on second-language acquisition. Journal of Memory and Language, 41, 78-104.

Floccia, C., Butler, J., Girard, F., \& Goslin, J. (2009). Categorization of regional and foreign accent in 5- to 7-year-old British children. International Journal of Behavioral Development, 33, 366-375.

Gardner, R. C. (1985). Social psychology and second language learning: The role of attitudes and motivation. London: Edward Arnold.

Gardner, R. C., \& Lambert, W. E. (1972). Attitudes and motivation in second-language learning. Rowley, MA: Newbury House.

Giles, H., \& Billings, A. (2004). Language attitudes. In A. Davies \& E. Elder (Eds.), The handbook of applied linguistics (pp. 187-209). Oxford, UK: Blackwell.

Gleitman, L. R., \& Newport, E. L. (1995). The invention of language by children: Environmental and biological influences on the acquisition of language. In L. Gleitman \& M. Liberman (Eds.), An invitation to cognitive science, Vol. 1: Language (2nd ed., pp. 1-24). Cambridge, MA: MIT Press.

Gluszek, A., Newheiser, A. K., \& Dovidio, J. F. (2011). Social psychological orientations and accent strength. Journal of Language and Social Psychology, 30, 28-45.

Harris, J. R. (2009). The nurture assumption: Why children turn out the way they do (2nd ed.). New York: Free Press.

Johnson, J. S., \& Newport, E. L. (1989). Critical period effects in second language learning: The influence of maturational state on the acquisition of English as a second language. Cognitive Psychology, 21, 60-99.

Jones, Z., Yan, Q., Wagner, L., \& Clopper, C. G. (2017). The development of dialect classification across the lifespan. Journal of Phonetics, 60, 20-37.

Kamwangamalu, N. M. (2003). Social change and language shift: South Africa. Annual Review of Applied Linguistics, 23, 225-242. 
Kinzler, K. D., Corriveau, K. H., \& Harris, P. L. (2011). Children's selective trust in nativeaccented speakers. Developmental Science, 14, 106-111.

Kinzler, K. D., \& DeJesus, J. M. (2013a). Children’s sociolinguistic evaluations of nice foreigners and mean Americans. Developmental Psychology, 49, 655-664.

Kinzler, K. D., \& DeJesus, J. M. (2013b). Northern = smart and Southern = nice: The development of accent attitudes in the U.S. Quarterly Journal of Experimental Psychology, 66, 1146-1158.

Kinzler, K. D., Dupoux, E., \& Spelke, E. S. (2007). The native language of social cognition. Proceedings of the National Academy of Sciences of the United States of America, 104, 1257712580.

Kinzler, K. D., Shutts, K., DeJesus, J., \& Spelke, E. S. (2009). Accent trumps race in guiding children's social preferences. Social Cognition, 27, 623-634.

Kinzler, K. D., Shutts, K., \& Spelke, E. S. (2012). Language-based social preferences among multilingual children in South Africa. Language Learning and Development, 8, 215-232.

Labov, W. (2009, March). What is to be learned? Paper presented at the 34th LAUD Symposium on Cognitive Sociolinguistics, Landau, Germany.

$<$ http://www.ling.upenn.edu/ wlabov/Papers/WTBL.pdf $>$.

Lambert, W. E., Hodgson, R., Gardner, R., \& Fillenbaum, S. (1960). Evaluational reactions to spoken languages. Journal of Abnormal and Social Psychology, 60, 44-51.

Nazzi, T., Bertoncini, J., \& Mehler, J. (1998). Language discrimination by newborns: Toward an understanding of the role of rhythm. Journal of Experimental Psychology: Human Perception and Performance, 24, 756-766.

Newport, E. L. (1990). Maturational constraints on language learning. Cognitive Science, 14, 11-28.

Nielsen, M., Haun, D., Kärtner, J., \& Legare, C. H. (2017). The persistent sampling bias in developmental psychology: A call to action. Journal of Experimental Child Psychology, 162, 3138.

Ochs, E., \& Schieffelin, B. (1995). The impact of language socialization on grammatical development. In P. Fletcher \& B. MacWhinney (Eds.), The handbook of child language (pp. 7394). Oxford, UK: Blackwell.

Ogunnaike, O., Dunham, Y., \& Banaji, M. R. (2010). The language of implicit preferences. Journal of Experimental Social Psychology, 46, 999-1003. 
Oller, D. K., \& Eilers, R. E. (2002). An integrated approach to evaluating effects of bilingualism in Miami school children: The study design. In D. K. Oller \& R. E. Eilers (Eds.), Language and literacy in bilingual children (pp. 22-40). Clevedon, UK: Multilingual Matters.

Olson, K. R., Shutts, K., Kinzler, K. D., \& Weisman, K. G. (2012). Children associate racial groups with wealth: Evidence from South Africa. Child Development, 83, 1884-1899.

Potter, C. E., \& Saffran, J. R. (2017). Exposure to multiple accents supports infants' understanding of novel accents. Cognition, 166, 67-72.

Ryan, C. (2013). Language use in the United States: 2011. American Community Survey Reports (U.S. Census Bureau). <https://www.census.gov/prod/2013pubs/acs-22.pdf>.

Shutts, K., Brey, E. L., Dornbusch, L. A., Slywotzky, N., \& Olson, K. R. (2016). Children use wealth cues to evaluate others. PLoS One, 11(3), e0149360.

Souza, A. L., Byers-Heinlein, K., \& Poulin-Dubois, D. (2013). Bilingual and monolingual children prefer native-accented speakers. Frontiers in Psychology, 4.

http://dx.doi.org/10.3389/fpsyg.2013.00953.

Taylor, D. M., Meynard, R., \& Rheault, E. (1977). Threat to ethnic identity and second-language learning. In H. Giles (Ed.), Language, ethnicity, and intergroup relations (pp. 99-118). London: Academic Press.

Wagner, L., Greene-Havas, M., \& Gillespie, R. (2010). Development in children’s comprehension of linguistic register. Child Development, 81, 1678-1686.

Weatherhead, D., White, K. S., \& Friedman, O. (2016). Where are you from? Preschoolers infer background from accent. Journal of Experimental Child Psychology, 143, 171-178.

Werker, J. F., \& Tees, R. C. (1984). Cross-language speech perception: Evidence for perceptual reorganization during the first year of life. Infant Behavior and Development, 7, 49-63.

Zajonc, R. B. (2001). Mere exposure: A gateway to the subliminal. Current Directions in Psychological Science, 10, 224-228. 